ISSN 0103-8478

\title{
Efeito in vitro de químicos no crescimento micelial de Saprolegnia spp.
}

\author{
In vitro effect of chemical on hyphal growth of Saprolegnia spp.
}

\author{
Bruna Ferraz Corrêa ${ }^{I}$ Franciele Elisa Stohl ${ }^{I}$ Ricardo Berteaux Robaldo ${ }^{I I}$ \\ Daniela Isabel Brayer Pereira ${ }^{I^{*}}$
}

\begin{abstract}
- NOTA -
RESUMO

Com o aumento da produtividade na piscicultura, os peixes são expostos a altas densidades de estocagem que podem levar ao estresse e imunossupressão. Essa condição favorece a ocorrência de infecções, entre elas a saprolegniose que afeta os peixes e seus ovos, causando sérios prejuizos econômicos aos piscicultores. Dessa forma, compostos químicos eficazes e "ambientalmente amigáveis" são almejados para o controle da doença. O objetivo do presente estudo foi avaliar a suscetibilidade in vitro de 12 isolados de Saprolegnia spp., provenientes dos peixes-rei dulceaquicolas Odontesthes bonariensis e O. humensis Para isso, testes de suscetibilidade, avaliando a inibição do crescimento micelial de Saprolegnia spp., foram realizados frente a seis químicos (cloreto de sódio, formaldeído, permanganato de potássio, iodopovidona, sal marinho e sal marinho iodado) nas concentrações seriadas de 0 a $10.000 \mathrm{ppm}$. Os resultados obtidos evidenciaram que o formaldeído e o permanganato de potássio, em concentrações a partir de 10 e acima de 100ppm, respectivamente, inibiram o crescimento micelial de isolados Saprolegnia spp.. Já a iodopovidona e os compostos salinos não evidenciaram atividade antimicrobiana em nenhuma das concentrações testadas

conditions determine the occurrence of a series of infections, including saprolegniosis. This disease affects fish and eggs from freshwater determining relevant economic losses to fish farmers. Thus, to avoid outbreaks, are being sought effective chemical agents that are "environmentally friendly". The aim of this study was to evaluate the in vitro susceptibility of 12 isolates of Saprolegnia spp. from the silversides Odontesthes bonariensis and o. humensis. Susceptibility tests evaluating inhibition of mycelial growth of Saprolegnia spp. were performed using six chemicals (sodium chloride, formaldehyde, potassium permanganate, povidone-iodine, sea salt and iodized sea salt) in concentrations from 0 to 10,000ppm. The results displayed that formaldehyde at the concentration of $10 \mathrm{ppm}$, and potassium permanganate at concentrations above 100ppm, were able to inhibit the mycelial growth of isolates of Saprolegnia spp. However, povidoneiodine and saline compounds exhibited no antimicrobial activity on Saprolegnia spp. Although the in vitro results showed that formaldehyde and potassium permanganate could be promising in controlling saprolegniosis, further studies should be performed to evaluate the in vivo efficacy of these compounds as well as to verify the toxicity of the chemicals to the silversides $\boldsymbol{O}$. bonariensis and O. humensis
\end{abstract} (0-10.000ppm). Embora os resultados in vitro demonstrem que formaldeido e permanganato de potássio sejam promissores no controle da saprolegniose, estudos futuros deverão avaliar a eficácia e o efeito in vivo desses compostos nos peixes-rei $\boldsymbol{O}$. bonariensis e $\mathrm{O}$. humensis.

Palavras-chave: Oomicetos, Odontesthes, saprolegniose, agentes químicos, suscetibilidade.

\section{ABSTRACT}

The productivity in fish farming has been increasing and consequently the fish are submitted to high stocking densities which usually cause stress and immunosuppression. These
Key words: Oomycetes, Odontesthes, saprolegniosis, chemical agents, susceptibility.

A aquicultura no Brasil vem apresentando crescimento acelerado, em especial a piscicultura, com a introdução de fazendas de criação em sistema superintensivo (FAO, 2011). Em produção superintensiva, os peixes são mantidos em elevada densidade de estocagem, o que predispõe ao estresse e imunossupressão. Essa condição favorece a

'Laboratório de Micologia, Instituto de Biologia, Departamento de Microbiologia e Parasitologia, Universidade Federal de Pelotas (UFPel), Campus Capão do Leão, Prédio 18, Sala 14, 96010-900, Capão do Leão, RS, Brasil. E-mail: danielabrayer@gmail.com. *Autor para correspondência.

"Laboratório de Ictiologia, Instituto de Biologia, Departamento de Fisiologia e Farmacologia, UFPel, Campus Capão do Leão, Capão do Leão, RS, Brasil. 
ocorrência de infecções, entre elas a saprolegniose, cujo agente etiológico é o oomiceto aquático Saprolegnia spp.. Os membros desse gênero são ubíquos em ecossistemas de água doce e no solo. Taxonomicamente, pertencem à divisão Oomycota, atualmente classificada no reino Straminipila. Inespecificamente, peixes e ovos de água doce podem ser infectados por esse oomiceto, que induz ao desenvolvimento de micélio branco-acinzentado na pele, nas brânquias e nos ovos, facilmente visíveis a olho nu (STUELAND et al., 2005). A doença ocasiona perdas massivas com sérios prejuízos econômicos aos piscicultores (WEST, 2006).

Odonthestes bonariensis(VALENCIENNES, 1835) e O. humensis (DE BUEN, 1953) são importantes espécies comerciais de peixe-rei em regiões subtropicais daAmérica do Sul. Ovos dessas espécies são naturalmente infectados pelos oomicetos Aphanomyces, Pythium, Leptomitus, Saprolegnia e Achlya (PACHECOMARINO et al., 2006).

Para o tratamento profilático, desinfecção e controle de infecções causadas por fungos aquáticos em peixes, vários agentes antimicrobianos têm sido testados. Verde de malaquita, formalina, peróxido de hidrogênio, permanganato de potássio, ácido acético e iodo podem ser mencionados entre os mais utilizados (FUANGSAWAT et al., 2011). Verde de malaquita é considerado o mais eficaz, no entanto, sua toxicidade e efeitos colaterais adversos inviabilizam seu uso. Esse fato impulsiona o desenvolvimento de pesquisas que buscam um químico eficaz e sem toxicidade para os animais e ambiente (FUANGSAWAT et al., 2011). Nesse sentido, vários estudos têm avaliado a eficácia in vivo de formaldeído, cloreto de sódio, permanganato de potássio e iodo para controle da saprolegniose em diversas espécies de peixes (RASOWO et al., 2007; KHODABANDEH \& ABTAHI, 2006).

$\mathrm{O}$ presente estudo objetivou avaliar a suscetibilidade in vitro de isolados de Saprolegnia spp., provenientes de peixes-rei frente aos químicos: cloreto de sódio, formaldeído, permanganato de potássio e iodeto de polivinilpirrolidona (PVPI).

Para os testes de suscetibilidade, foram utilizados 12 isolados de Saprolegnia spp., obtidos de ovos infectados dos peixes-rei $\boldsymbol{O}$. bonariensis e O. humensis ( $\mathrm{n}=3$ para cada espécie) e seis isolados oriundos da água dos tanques de incubação. Para o isolamento do oomiceto, a partir da água de incubação, procedeu-se à coleta de $200 \mathrm{~mL}$ de água de seis tanques. A cada amostra, acrescentaram-se sementes de gergelim (Sesamum indicum L.) como iscas e imediata incubação em estufa bacteriológica durante 2 a 5 dias a $25^{\circ} \mathrm{C}$. Após esse período, as sementes parasitadas foram transferidas para placas de petri contendo agar levedura $2 \%$, acrescido de antibióticos. Seis amostras de ovos, três de cada espécie de peixe-rei, parasitadas por micélio branco, algodonoso foram semeadas no mesmo meio de cultura utilizado anteriormente. Todas as placas foram incubadas em estufa bacteriológica a $25^{\circ} \mathrm{C}$, durante 2 a 5 dias. As colônias suspeitas foram submetidas à identificação morfológica, levandose em consideração a morfologia das hifas e das estruturas de reprodução assexuada. Os químicos cloreto de sódio, formaldeído, permanganato de potássio, PVPI e sal marinho com e sem iodo foram utilizados nas concentrações de 0, 10, 50, 100, 1000, 5000 e $10000 \mathrm{ppm}$. Cada concentração avaliada foi misturada a $20 \mathrm{~mL}$ de agar levedura a $45^{\circ} \mathrm{C}$. Após a homogenização e solidificação do agar, um disco de $9 \mathrm{~mm}$ de diâmetro do cultivo do oomiceto foi semeado na posição central da placa e incubada em estufa bacteriológica a $25^{\circ} \mathrm{C}$, durante quatro dias. Como controle positivo, utilizou-se a concentração $0 \mathrm{ppm}$ de cada químico e, como controle negativo, foi utilizado o meio de cultivo, sem o oomiceto. Diariamente, por quatro dias, o crescimento micelial de Saprolegnia spp. foi avaliado por meio da medida do diâmetro do halo de crescimento. Todos os testes foram realizados em duplicata. O Índice de Velocidade de Crescimento Micelial (IVCM) foi baseado na velocidade de crescimento do micélio a cada dia. Os resultados foram analisados por ANOVA de uma via, seguida do teste de diferença de médias de Tukey HSD, sob nível de significância de 5\%.

Os dados do crescimento micelial dos 12 isolados de Saprolegnia spp. são apresentados na tabela 1. Observou-se que o formaldeído inibiu o crescimento do oomiceto em concentrações a partir de 10ppm. Já o permanganato de potássio evidenciou ação antimicrobiana, tanto nas amostras oriundas de água quanto nas de ovos de $\boldsymbol{O}$. bonariensis, em concentrações a partir de $1000 \mathrm{ppm}$, enquanto que, nos isolados provenientes de $\boldsymbol{O}$. humensis, a atividade foi efetiva a partir de 100ppm. Tanto o PVPI como os sais (cloreto de sódio puro, sal marinho e sal marinho iodado) não apresentaram eficácia nas concentrações testadas.

No Brasil, MARTINS et al. (2002) citam a ocorrência de saprolegniose em peixes de água doce das espécies pacu (Piaractus mesopotamicus), piavuçu (Leporinus macrocephalus), tambacu híbrido e tilápia (Oreochromis niloticus), no estado de São Paulo. No presente estudo, Saprolegnia spp. foi isolada de amostras de ovos de $\boldsymbol{O}$. bonariensis e $\boldsymbol{O}$. humensis e de água de tanques coletadas de um 
Tabela 1 - Efeito de agentes químicos no índice de velocidade de crescimento micelial (IVCM; média \pm DP) de isolados de Saprolegnia spp. Obtidos a partir de água de cultivo (AC) e de ovos dos peixes-rei Odontesthes bonariensis (OB) e O. humensis (OH).

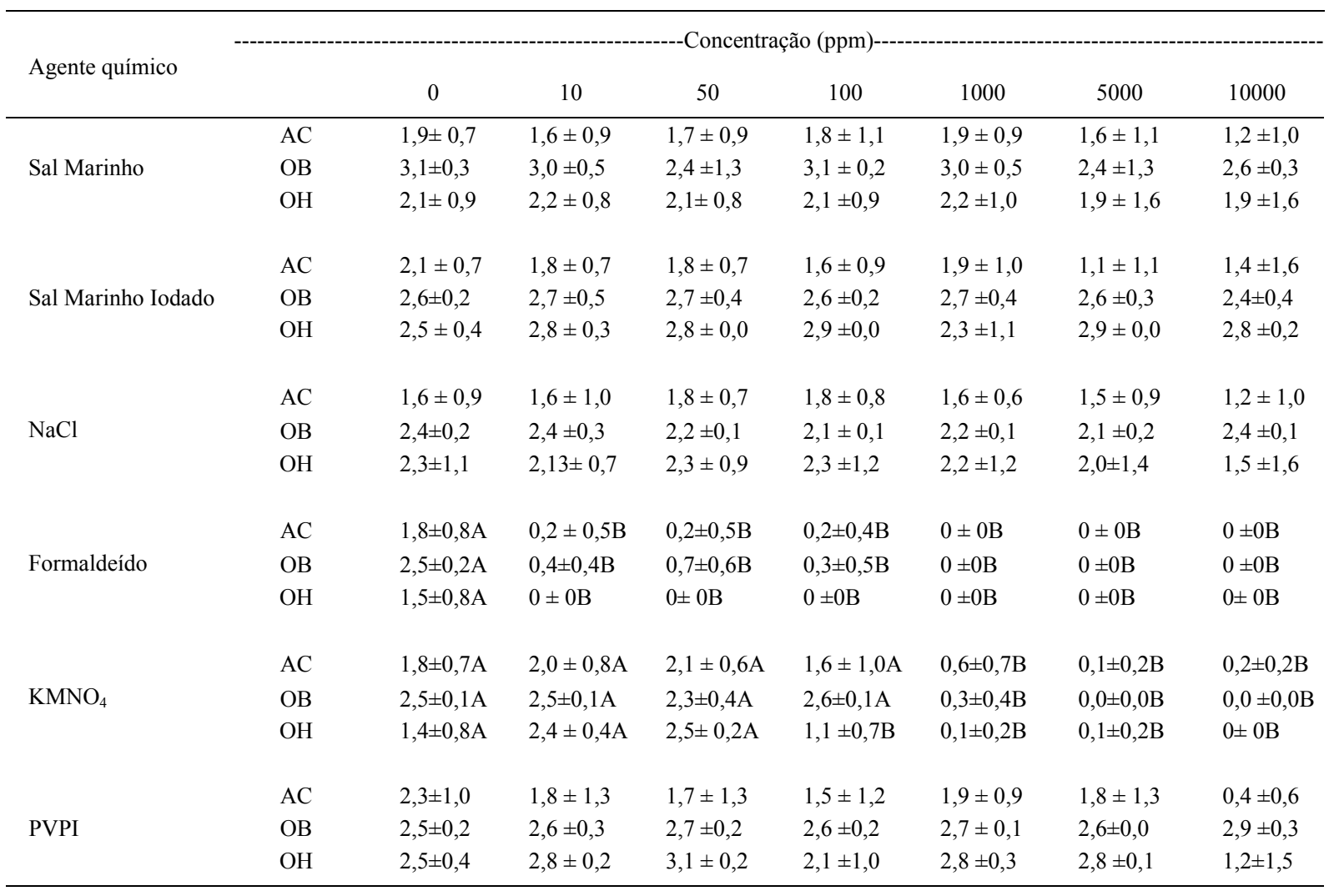

Letras maiúsculas distintas demonstram diferenças significativas (ANOVA fatorial, Tukey HSD, $\mathrm{P}<0,05$ ) entre as médias para o mesmo isolado nas linhas. $\mathrm{KMNO}_{4}=$ permanganato de potássio, PVPI= iodeto de polivinilpirrolidona.

sistema de produção experimental de peixes no sul do Rio Grande do Sul. Esses achados evidenciam a ocorrência de saprolegniose em peixes de água doce neste Estado e justificam a procura por métodos de controle da enfermidade no intuito de reduzir as perdas causadas pela infecção.

Os resultados mostram que os químicos, formaldeído e permanganato de potássio, inibiram o crescimento micelial de todos os isolados de Saprolegnia spp. avaliados. Já, PVPI e os compostos salinos não evidenciaram inibição do oomiceto em nenhuma das concentrações testadas. O formaldeído é conhecido como potente fungicida, sendo registrado e aprovado para uso no controle de infecções fúngicas em ovos de salmonídeos (PACHECO-MARINO \& SALIBIAN, 2010). Neste estudo, o químico inibiu todos os isolados de Saprolegnia spp. a partir de 10ppm. Em trabalhos com efeitos toxicológicos em peixes, é relatado que o formol pode ser usado em concentrações de até 530ppm sem provocar danos ao peixe-rei $\boldsymbol{O}$. bonariensis (PACHECO-MARINO \&
SALIBIAN, 2010). Dessa forma, os resultados in vitro obtidos no presente estudo sugerem que o formaldeído pode ser empregado em baixas concentrações para o controle de saprolegniose em peixe-rei. Todavia, é importante o desenvolvimento de estudos in vivo para avaliar a eficácia dessa concentração na profilaxia da doença em peixe-rei. Observou-se que o permanganato de potássio promoveu inibição em concentrações a partir de 1000ppm nos isolados oriundos de ovos de O. bonariensis e das águas de incubação e a partir de $100 \mathrm{ppm}$ nos isolados provenientes de ovos de $\boldsymbol{O}$. humensis. Essas respostas diferem daquelas obtidas in vivo, que afirmam que concentrações de 2 ppm são eficazes para tratamento de ovos de truta (RASOWO et al., 2007). Por outro lado, MARKING et al. (1994), ao utilizar concentrações de 50 e 100 ppm de permanganato de potássio para tratamento de ovos de truta arco-íris (Oncorhynchus mykiss), observou que esse químico, além de não controlar a infecção por Saprolegnia, causou atraso na eclosão dos ovos. Assim, independente do resultado obtido no

Ciência Rural, v.43, n.6, jun, 2013. 
experimento in vitro, estudos in vivo para avaliar a eficácia desse composto no controle de saprolegniose, bem como sua toxicidade para $\boldsymbol{O}$. bonariensis e $\boldsymbol{O}$. humensis são necessários. Nas condições em que o estudo foi realizado, PVPI (10\% de iodo) não evidenciou contribuição significativa para o controle de Saprolegnia spp. Esses resultados diferem de pesquisas prévias que utilizaram PVPI na inibição do crescimento micelial de Saprolegnia spp., Achyla spp. e Aphanomyces spp. (FUANGSAWAT et al., 2011). Quando avaliada a atividade dos compostos salinos, observou-se que não houve inibição do crescimento micelial do oomiceto, em nenhuma das concentrações testadas. Resultados similares foram relatados por FUANGSAWAT et al. (2011). Embora MARKING et al. (1994) e KHODABANDEH \& ABTAHI (2006) afirmem que concentrações de 3 e $3,5 \%$ de cloreto de sódio sejam eficazes na prevenção da infecção em ovos de truta arco-íris e carpa comum, os resultados obtidos no presente estudo evidenciam que as concentrações dos compostos salinos avaliados encontram-se acima das relatadas por esses autores. Dessa forma, acredita-se que o emprego desses compostos no controle da enfermidade em peixerei torna-se inviável, uma vez que as concentrações necessárias para a inibição do crescimento do oomiceto encontram-se bem acima dos níveis de tolerância para o peixe-rei (PACHECO-MARINO \& SALIBIAN, 2010).

Os resultados obtidos demonstram que os compostos formaldeído e permanganato de potássio são eficazes na inibição in vitro do crescimento micelial de isolados de Saprolegnia spp. provenientes dos peixes-rei $\boldsymbol{O}$. bonariensis e $\boldsymbol{O}$. humensis. No entanto, estudos deverão ser realizados para avaliar a eficácia in vivo desses compostos no controle da saprolegniose, assim como verificar a toxicidade dos químicos a essas espécies de peixe-rei.

\section{REFERÊNCIAS}

FOOD AND AGRICULTURE ORGANIZATION OF THE UNITED NATIONS. World aquaculture 2010. Rome: Fisheries and Aquaculture Department, FAO, 2011. 105p. (Technical Paper No. 500/1). Disponível em: <http://www.fao.org/docrep/014/ ba0132e/ba0132e00.htm>. Acesso em: 07 dez. 2012.

FUANGSAWAT, W. et al. Sensitivity comparison of pathogenic aquatic fungal hyphae to sodium chloride, hydrogen peroxide, acetic acid and povidone iodine.v Kasetsart Journal of Natural Science, v.45, p.84-89, 2011. Disponível em: $<$ http://research.rdi. ku.ac.th/world/showItem.php?itemID $=118700>$. Acesso em: 07 dez. 2012.

KHODABANDEH, S.; ABTAHI, B. Effect of sodium chloride, formalin and iodine on the hatching success of common carp, Cyprinus carpio, eggs. Journal of Applied Ichthyology, v.22, n.1, p.54-56, 2006. Disponível em: <http://onlinelibrary.wiley. com/doi/10.1111/j.1439-426.2006.00662.x/abstract;jsessionid=49 07B637CDF11087FEBCAE1A77D4D3E5.d03t04>. Acesso em: $22 \mathrm{dez}, 2012$. doi: 10.1111/j.1439-0426.2006.00662.x.

MARKING et al. Evaluation of antifungal agents for fish culture. American Fisheries Society Evaluation of Antifungal Agents for Fish Culture, v.56, p.225-231, 1994. Disponível em: $<$ http://www.tandfonline.com $>$. Acesso em: 28 set, 2012. doi: 10.1577/1548-40(1994)056<0225:AFSEOA >2.3.CO;2.

MARTINS, M.L. et al. Recent studies on parasitic infections of freshwater cultivated fish in the state of São Paulo, Brazil. Acta Scientiarum, v.24, n.4, p.981-985, 2002. Disponível em: $<\mathrm{http} / /$ www.google.com.br>. Acesso em: 18 ago. 2012.

PACHECO-MARINO, S.G.; SALIBIAN, A. Acute toxicity of three antifungal chemicals on silverside Odontesthes bonariensis (Valenciennes, 1835) eggs. International Journal of Enviromental and Health, v.4, n.4, p.333-341, 2010. Disponível em: <http://www.inderscience.com>. Acesso em: 23 abr. 2012. doi: 10.1504/IJENVH.2010.037498.

PACHECO-MARINO, S.G. et al. Aproximación a la caracterización de la micobiota parásita de ovas fecundadas de pejerrey Odontesthes bonariensis. In: NATIONAL CONGRESS OF CONSERVATION AND BIODIVERSITY, 2., 2006, Buenos Aires, Argentina. Abstracts II. Buenos Aires: National Congress of Conservation and Biodiversity, 2006. 190p. p.188.

RASOWO, J. et al. Effects of formaldehyde, sodium chloride, potassium permanganate and hydrogen peroxide on hatch rate of African catfish Clarias gariepinus eggs. Aquaculture, v.269, p.271-277, 2007. Disponível em: <http://www.sciencedirect. com/science/article/pii/S0044848607004115>. Acesso em: 17 abr. 2012. doi: 10.1016/j.aquaculture.2007.04.087.

STUELAND, S. et al. Morphological and physiological characteristics of Saprolegnia spp. strains pathogenic to Atlantic salmon, Salmo salar L. Journal of Fish Diseases, v.28, p.445453, 2005. Disponível em: <http://onlinelibrary.wiley.com/ doi/10.1111/jfd.2005.28.issue-8/issuetoc $>$. Acesso em: 17 out. 2012. doi: $10.1111 / j .1365-2761.2005 .00635 . x$.

WEST, P. Saprolegnia parasitica, an oomycete pathogen with a fishy appetite: new challenges for an old problem. Mycologist, v.20, p.99-104, 2006. Disponível em: $<$ http://www.sciencedirect. com/science/article/pii/S0269915X0600053X >. Acesso em: 17 abr. 2012. doi: 10.1016/j.mycol.2006.06.004. 